\section{Case Reports in Ophthalmology}

Case Rep Ophthalmol 2018;9:120-125

DOI: 10.1159/000485912

\title{
Central Serous Chorioretinopathy Associated with Desmopressin Nasal Spray: Causality or Unfortunate Association
}

\author{
Nacima Kisma Eleni Loukianou Bishwanath Pal \\ Moorfields Eye Hospital NHS, London, UK
}

\section{Keywords}

Desmopressin · Central serous chorioretinopathy · Endogenous cortisol

\begin{abstract}
Purpose: To describe the possible association between central serous chorioretinopathy (CSCR) and desmopressin use. Methods: The case histories of 2 middle-aged men with CSCR using desmopressin nasal spray were studied. Results: The diagnosis of CSCR was made on the basis of clinical features and ancillary testing (fluorescein angiography and optical coherence tomography). Both patients were using desmopressin nasal spray for polyuria when they developed the first ocular symptoms. Both of them also had an independent risk factor for developing CSCR. Conclusion: We suggest that desmopressin-induced hypercortisolism might implicate the development of CSCR in some patients. A larger study on patients using desmopressin nasal spray would be beneficial to confirm the possible association between this form of therapy and the development of CSCR.

(C) 2018 The Author(s) Published by S. Karger AG, Basel
\end{abstract}

\section{Introduction}

Desmopressin (1-desamino-8-D-arginine vasopressin, DDAVP) is a synthetic analogue of arginine vasopressin being used for the treatment of central diabetes insipidus, bed-wetting, and some coagulation disorders such as von Willebrand disease, mild haemophilia A, and 


\section{Case Reports in Ophthalmology}

\begin{tabular}{l|l}
\hline DOI: $10.1159 / 000485912$ & (C) 2018 The Author(s). Published by S. Karger AG, Basel \\
www.
\end{tabular} www.karger.com/cop

Kisma et al.: Central Serous Chorioretinopathy Associated with Desmopressin Nasal Spray: Causality or Unfortunate Association

thrombocytopenia. Desmopressin binds to V2 receptors in renal collecting ducts increasing water reabsorption. It also stimulates the release of factor VIII from endothelial cells due to stimulation of the V1a receptor. It is known to be more potent at the V2 than the V1a receptor. V3 receptors are found in the anterior pituitary and they have a role in the secretion of adrenocorticotrophic hormone (ACTH). After its binding to V3 receptors in corticotrophs, the synthesis of pro-opiomelanocortin (POMC), a precursor of ACTH, is stimulated. This suggests that DDAVP is capable of stimulating ACTH and cortisol release.

\section{Case Presentations}

The case histories of 2 middle-aged men with central serous chorioretinopathy (CSCR) using desmopressin nasal spray were studied. The diagnosis of CSCR was made on the basis of clinical features and ancillary testing.

The first patient is a forklift truck driver. He is hyperopic and has a right amblyopia. He underwent squint surgery when he was 16 years old. He was not taking any medication and he first experienced some visual disturbances when he was 38 years old. He was started on desmopressin nasal spray because of detrusor instability 20 years ago. His most recent Snellen visual acuity was $6 / 9$ on the right and $6 / 6$ on the left. The fundus examination revealed multiple pigmentary changes bilaterally, best seen on autofluorescence imaging and subretinal fluid during the follow-up period (Fig. 1a, b). He was further investigated with fluorescein angiogram which showed staining of the lesions without leakage (Fig. 2a, b). He underwent focal laser treatment in his left eye and a regular follow-up was recommended. The second patient has a diagnosis of diabetes insipidus. He had been using desmopressin nasal spray since 2007. He was also making intermittent use of hydrocortisone because of low endogenous cortisol levels. He was first reporting visual symptoms at the age of 43, in July 2009. His most recent Snellen visual acuity was $6 / 12$ on the right and $6 / 6$ on the left. The clinical fundus examination revealed pigmentary changes in both eyes. The optical coherence tomography revealed a retinal pigment epithelium detachment and subretinal fluid in both eyes (Fig. 3a, b).

\section{Discussion}

CSCR has been reported to be associated with endogenous hypercortisolism such as Cushing disease, type A behaviour and pregnancy, administration of ACTH or exogenous administration of corticosteroids [1-8]. Our first patient had been making use of desmopressin nasal spray for more than 20 years. Our second patient had been using desmopressin nasal spray for 10 years.

A cortisol or ACTH response to intravenous administration of desmopressin has been described by several authors. Rado and Juhos [9] found that a dose of $4 \mu \mathrm{g}$ of desmopressin administered intravenously induced an increase of plasma cortisol levels in 12 out of 20 subjects studied. Malerbi et al. [10] also reported that 2 out of 15 normal subjects receiving intravenous desmopressin had a cortisol level increased by 58 and $69 \%$ above baseline, respectively. Terzolo et al. [11] reported a 13\% increase of ACTH in healthy subjects following the administration of desmopressin.

Moreover, Scott et al. [12] studied ACTH and cortisol release following intravenous administration of desmopressin in 18 healthy subjects. They observed that DDAVP is capable 
of stimulating ACTH and cortisol release when administered alone as a bolus in over $50 \%$ of healthy subjects, but found, like Rado et al., that the mode of administration may be pertinent to this effect. Desmopressin can induce an increase in endogenous cortisol in some patients and has been found to be increased in patients with CSCR by Garg et al. [13] and Haimovici et al. [14].

The UK health and care regulatory agency had 2 cases of blurred vision and 1 case of vision impairment reported in patients on desmopressin between July 1, 1963 and July 14, 2010.

We suggest that desmopressin-induced hypercortisolism might implicate the development of CSCR in some patients. A larger study on patients using desmopressin nasal spray would be beneficial to confirm the possible association between this form of therapy and the development of CSCR.

\section{Statement of Ethics}

The patients have given their informed consent.

\section{Disclosure Statement}

The research was funded by the National Institute for Health Research (NIHR) Biomedical Research Centre at Moorfields Eye Hospital NHS Foundation Trust and UCL Institute of Ophthalmology.

\section{References}

1 Thoelen AM, Bernasconi PP, Schmid C, Messmer EP: Central serous chorioretinopathy associated with a carcinoma of the adrenal cortex. Retina 2000;20:98-99.

2 Zamir E: Central serous retinopathy associated with adrenocorticotrophic hormone therapy. A case report and hypothesis. Graefes Arch Clin Exp Ophthalmol 1997;235:339-344.

3 Bouzas EA, Karadimas P, Pournaras CJ: Central serous chorioretinopathy and glucocorticoids. Surv Ophthalmol 2002;47:431-448.

4 Wakakura M, Ishikawa S: Central serous chorioretinopathy complicating systemic corticosteroid treatment. Br J Ophthalmol 1984;68:329-331.

-5 Gass JDM, Little H: Bilateral bullous exudative retinal detachment complicating idiopathic central serous chorioretinopathy during systemic corticosteroid therapy. Ophthalmology 1995;102:737-747.

6 Haimovici R, Gradoudas ES, Duker JS, et al: Central serous chorioretinopathy associated with inhaled or intranasal corticosteroids. Ophthalmology 1997;104:1653-1660.

7 Kao LY: Bilateral serous retinal detachment resembling central serous chorioretinopathy following epidural steroid injection. Retina 1998;18:479-481.

8 Karadimas P, Kapetanios A, Bouzas EA: Central serous chorioretinopathy after local application of glucocorticoids for skin disorders. Arch Ophthalmol 2004;122:784-786.

-9 Rado JP, Juhos E: Effect of 1-deamino-5-D-arginine vasopressin (DDAVP) on plasma cortisol (hydrocortisone). J Clin Pharmacol 1976;16:333-337.

10 Malerbi DA, Mendonça BB, Liberman B, Toledo SP, Corradini MC, Cunha-Neto MB, Fragoso MC, Wajchenberg BL: The desmopressin stimulation test in the differential diagnosis of Cushing's syndrome. Clin Endocrinol (Oxf) 1993;38:463-472.

11 Terzolo M, Reimondo G, Alì A, Borretta G, Cesario F, Pia A, Paccotti P, Angeli A: The limited value of the desmopressin test in the diagnostic approach to Cushing's syndrome. Clin Endocrinol (Oxf) 2001;54:609-616.

12 Scott LV, Medbak S, Dinan TG: ACTH and cortisol release following intravenous desmopressin: a doseresponse study. Clin Endocrinol (Oxf) 1999;51:653-658. 


\section{Case Reports in Ophthalmology}

\begin{tabular}{l|l}
\hline DOI: $10.1159 / 000485912$ & $\begin{array}{l}\text { ( ) 2018 The Author(s). Published by S. Karger AG, Basel } \\
\text { www.karger.com/cop }\end{array}$ \\
\hline
\end{tabular}

Kisma et al.: Central Serous Chorioretinopathy Associated with Desmopressin Nasal Spray: Causality or Unfortunate Association

13 Garg SP, Dada T, Talwar D, Biswas NR: Endogenous cortisol profile in patients with central serous chorioretinopathy. Br J Ophthalmol 1997;81:962-964.

14 Haimovici R, Rumelt S, Melby J: Endocrine abnormalities in patients with central serous chorioretinopathy. Ophthalmology 2003;110:698-703.
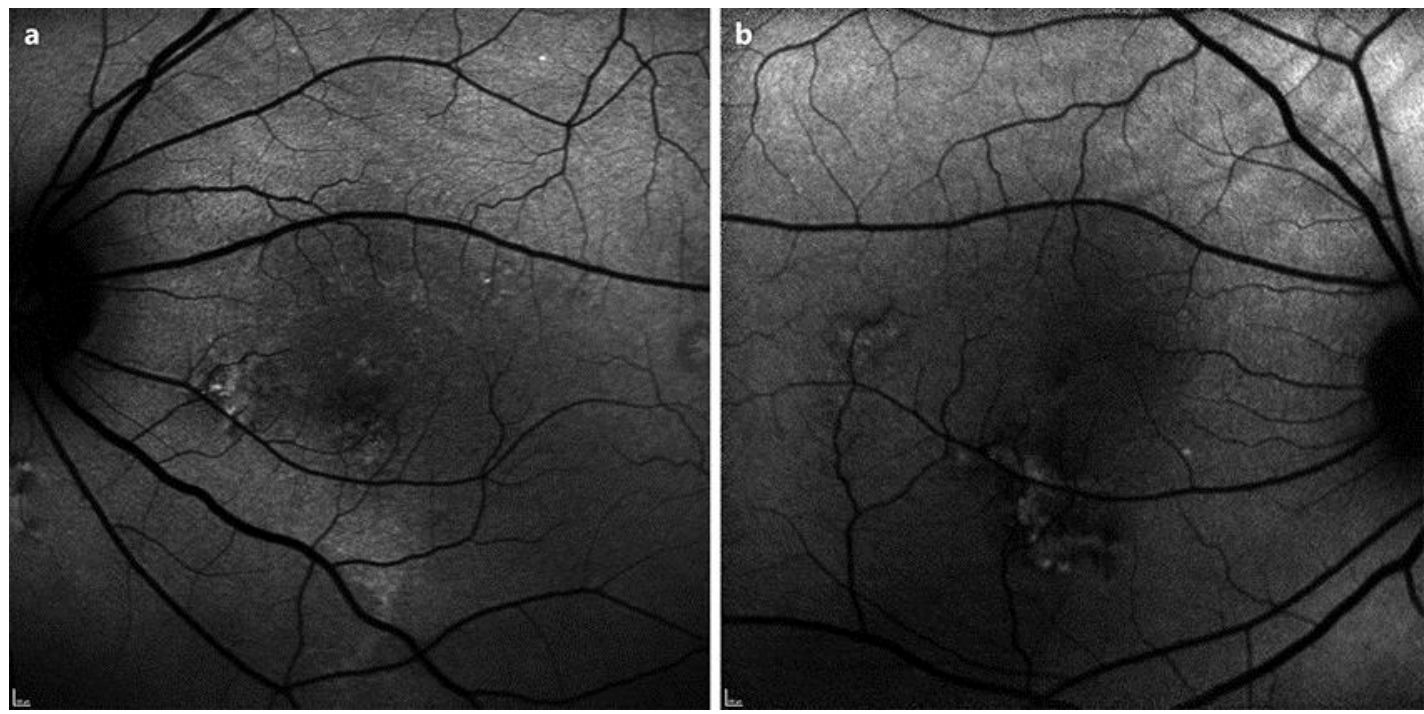

Fig. 1. a, b Autofluorescence showing bilateral macular pigmentary changes. 


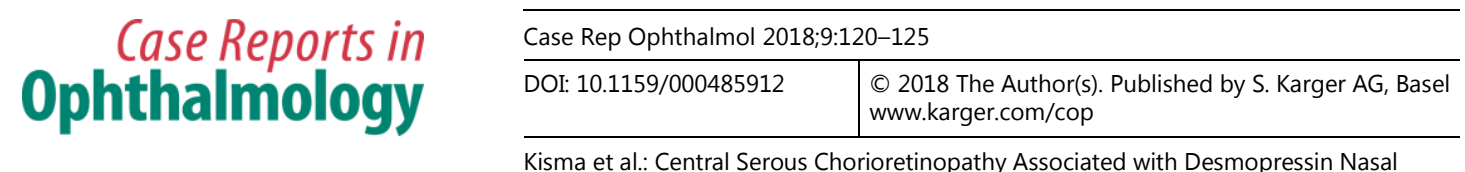
Spray: Causality or Unfortunate Association
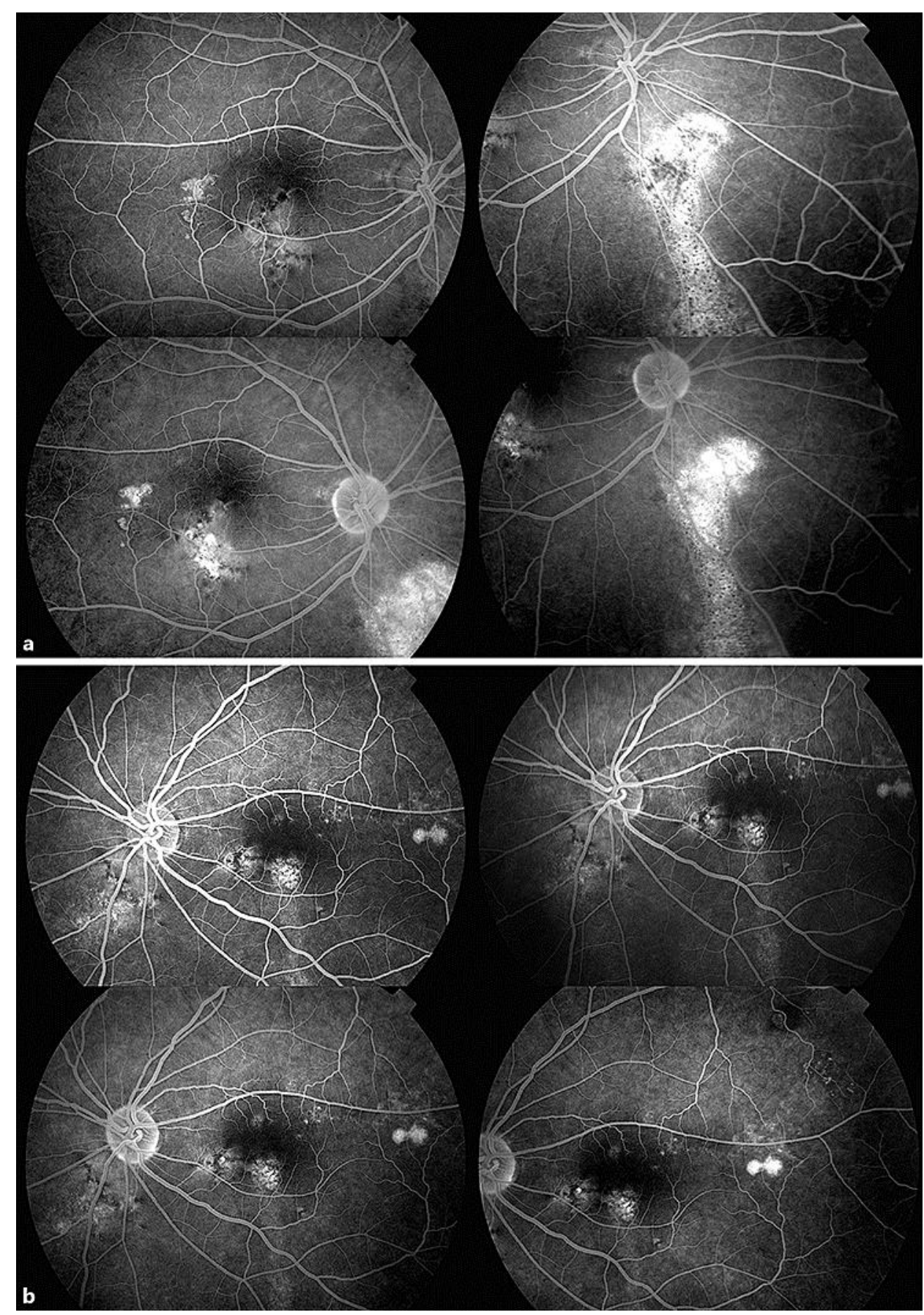

Fig. 2. a, b Fluorescein angiogram showing staining of the lesions in the right (a) and left (b) eye. 


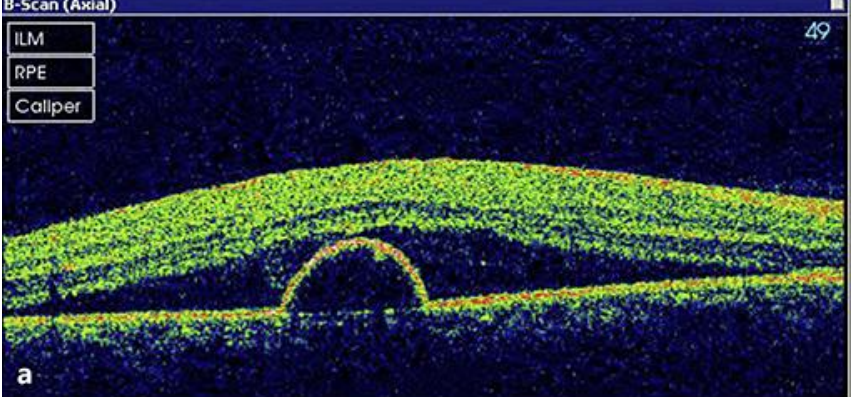

Kisma et al.: Central Serous Chorioretinopathy Associated with Desmopressin Nasal Spray: Causality or Unfortunate Association
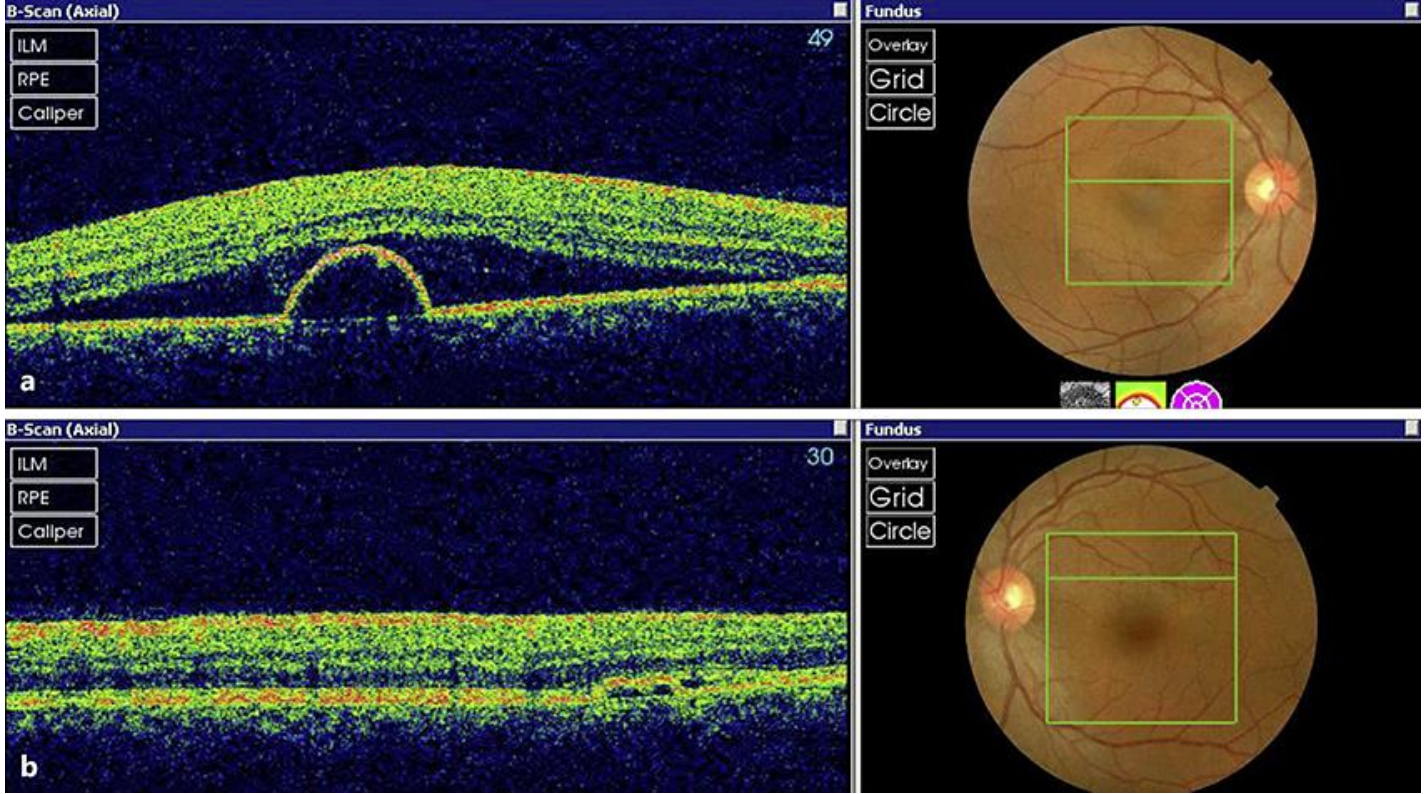

Fig. 3. a, b Optical coherence tomography of the right eye (a) and left eye (b) showing pigment epithelium detachment and subretinal fluid. 